\title{
A study of aerosol liquid water content based on hygroscopicity measurements at high relative humidity in the North China Plain
}

\author{
Y. X. Bian ${ }^{1}$, C. S. Zhao ${ }^{1}$, N. Ma ${ }^{1,2}$, J. Chen ${ }^{1}$, and W. Y. Xu ${ }^{1}$ \\ ${ }^{1}$ Department of Atmospheric and Oceanic Sciences, School of Physics, Peking University, Beijing 100871, China \\ ${ }^{2}$ Leibniz Institute for Tropospheric Research, Permoserstr. 15, 04318 Leipzig, Germany \\ Correspondence to: C. S. Zhao (zcs@pku.edu.cn)
}

Received: 28 November 2013 - Published in Atmos. Chem. Phys. Discuss.: 14 February 2014

Revised: 6 May 2014 - Accepted: 21 May 2014 - Published: 26 June 2014

\begin{abstract}
Water can be a major component of aerosol particles, also serving as a medium for aqueous-phase reactions. In this study, a novel method is presented to calculate the aerosol liquid water content at high relative humidity based on measurements of aerosol hygroscopic growth factor, particle number size distribution and relative humidity in the Haze in China (HaChi) summer field campaign (July-August 2009) in the North China Plain. The aerosol liquid water content calculated using this method agreed well with that calculated using a thermodynamic equilibrium model (ISORROPIA II) at high relative humidity $(>60 \%)$ with a correlation coefficient of 0.96 . At low relative humidity $(<60 \%)$, an underestimation was found in the calculated aerosol liquid water content by the thermodynamic equilibrium model. This discrepancy mainly resulted from the ISORROPIA II model, which only considered limited aerosol chemical compositions. The mean and maximum values of aerosol liquid water content during the HaChi campaign reached $1.69 \times 10^{-4} \mathrm{~g} \mathrm{~m}^{-3}$ and $9.71 \times 10^{-4} \mathrm{~g} \mathrm{~m}^{-3}$, respectively. A distinct diurnal variation of the aerosol liquid water content was found, with lower values during daytime and higher ones at night. The aerosol liquid water content depended strongly on the relative humidity. The aerosol liquid water content in the accumulation mode dominated the total aerosol liquid water content.
\end{abstract}

\section{Introduction}

Water uptake by a dry particle composed of inorganic salts takes place at a critical relative humidity - namely, deliquescence relative humidity (DRH) (Seinfeld and Pandis, 2006).
As the relative humidity (RH) increases, the hygroscopic growth of aerosols will continue and become even much faster when RH exceeds $80 \%$ (Engelhart et al., 2011). Once the ambient RH reaches the critical supersaturation ratio of aerosol particles, aerosols are activated into cloud droplets. Water uptake by aerosol particles exerts an influence on aerosol optical properties, leading to increased extinction coefficient and impaired atmospheric visibility, changing the planetary albedo, aerosol optical depth (AOD), and the direct climatic effect of aerosols (Dougle et al., 1996; Seinfeld and Pandis, 2006). Aerosol liquid water content (ALWC) can also speed up the atmospheric chemical reaction rates and serve as the medium for air-particle heterogeneous reactions (Arellanes et al., 2006).

ALWC mostly depends on aerosol hygroscopicity and the ambient RH. Under ambient RH higher than $90 \%$, liquid water makes up a great part of the aerosol volume (Kitamori et al., 2009). Although the mass concentration of ALWC under sub-saturated conditions is much lower than the liquid water contents in clouds or fogs, ALWC plays an important role in the tropospheric chemistry (Gelencsér and Varga, 2005). ALWC has a significant effect on the phase partitioning of trace substances and the chemical reactions that take place inside or on the surface of particulate matter (Kreidenweis et al., 2008).

ALWC can be calculated with detailed aerosol chemical information. However, simulations of aerosol hygroscopicity and phase state could still be quite complicated even under the thermodynamic equilibrium hypothesis. On one hand, ions could be combined in various ways into a variety of solid components. On the other hand, the behaviour of the liquidphase substances in the aerosol are highly non-ideal due to 
the high concentrations of solutes under low RH (Wexler and Clegg, 2002). Various aerosols can exist in a metastable liquid state under the condition that dissolved salts are supersaturated, which makes it even more complicated for the simulation process (Martin, 2000). Many aerosol thermodynamic equilibrium models have been developed to simulate the process of aerosols dissolving in water and forming ions, including EQUIL, MARS, AIM, E-AIM, SCAPE, EQUISOLV, ISORROPIA etc. (Bassett and Seinfeld, 1983; Saxena et al., 1986; Wexler and Seinfeld, 1991; Kim et al., 1993; Jacobson et al., 1996; Nenes et al., 1998; Wexler and Clegg, 2002). Zhang et al. (2000) compared the simulation results of some of the above-mentioned models. Most models only consider how inorganic solutes influence the saturation vapour pressure as solute (Raoult effect). Topping et al. (2005a, b) developed a model called ADDEM, which considers both the Raoult effect and the curvature effect of the organic/inorganic aerosol components. Chang et al. (2001) calculated the purely theoretical water content of ambient aerosols with the ISORROPIA model to adjust the discrepancy of $\mathrm{PM}_{10}$ (particles with aerodynamic diameter equal to or less than $10 \mu \mathrm{m}$ ) concentrations between the results measured by the $\beta$-gauge monitor and sampled by the hi-vol sampler. Hennigan et al. (2008) predicted the liquid water concentration with the ISORROPIA II thermodynamic equilibrium model, using mean sulfate, nitrate, and ammonium concentrations from the August 1999 Atlanta Supersite data. Though the model does not consider the effect of organics on water uptake, they thought that the high inorganic concentrations of $\mathrm{PM}_{2.5}$ (particles with aerodynamic diameter equal to or less than $2.5 \mu \mathrm{m}$ ) suggest that the model results provide a reasonable estimate.

Another way to obtain the ALWC is based on sizeresolved aerosol hygroscopic growth factors and particle number size distributions (PNSDs). Aklilu et al. (2006) used the Quadrupole Aerosol Mass Spectrometer (Q-AMS) to measure size-resolved aerosol chemical component information and assumed constant growth factors for organic compositions. A simplified model that is based on the ZdanovskiiStokes-Robinson (ZSR; Stokes and Robinson, 1966) mixing rule (the hygroscopicity of mixed aerosols is computed by weighting hygroscopicity of each component according to their dry volume fractions) is then applied to simulate the aerosol growth factors. The comparison between the simulated growth factors and those measured by the Hygroscopicity Tandem Differential Mobility Analyser (H-TDMA) shows that, for aerosols with sulfate as main inorganic component, the simulated result is similar to the measured one. For aerosols with large proportions of nitrate in the inorganic compositions, the simulated result is higher than the measurement. Similar results have been reported by Gysel et al. (2007). With aerosol chemical components from sizesegregated filter sampling, Meier et al. (2009) calculated the aerosol growth factors at different particle sizes with a model and then compared it respectively with the H-TDMA and Hu- midifying Differential Mobility Particle Sizer measurements. The modelling results based on measured chemical components could only reproduce the hygroscopic growth factors' variation pattern with size as was observed by the other two methods.

Combining the aerosol PNSD with the aerosol hygroscopic growth characteristics, real-time ALWC can be calculated. Engelhart et al. (2011) used the Dry-Ambient Aerosol Size Spectrometer to observe the volume growth factor after aerosol water uptake, and then combined it with the PNSD measured by a Scanning Mobility Particle Sizer to calculate the ALWC. Comparison between the results calculated with volume growth factor and PNSD and the ALWC measured by a Q-AMS that directly collected ambient aerosol in the same field campaign was made. Comparison results displayed a similar variation pattern of growth factors with size. However, the absolute values showed great discrepancies. For ambient RH greater than $70 \%$, the RH values which were recorded by the sensors on the Dry-Ambient Aerosol Size Spectrometer and Q-AMS showed outstanding differences, which is why the data observed under $\mathrm{RH}>70 \%$ were discarded in their research.

With increasing RH, aerosols will grow in size due to hygroscopic growth processes (Cheng et al., 2008). Especially under high RH (RH > $90 \%)$, a rapid increase of aerosol hygroscopic growth factors (Liu et al., 2011) and aerosol extinction coefficients (Chen et al., 2012) were found, which will lead to more significant impacts of aerosols on climate. Therefore, the study of ALWC under high RH conditions is particularly important. However, only limited research has been performed on this subject. Jung et al. (2009) did a comparative analysis about aerosol mass scattering efficiency and single scattering albedo at both ambient and dry $\mathrm{RH}$ in the Pearl River Delta, China, and then used the result to represent the effect of ALWC on visibility and radiative forcing. The highest RH value was beyond $90 \%$ during the campaign. Instead of calculating the ALWC to quantify the effect of ALWC on visibility and radiative forcing, they only used the ambient RH as a proxy for ALWC to make qualitative descriptions. Kreidenweis et al. (2008) measured the hygroscopic properties of several compounds (sodium chloride $(\mathrm{NaCl})$, ammonium sulfate $\left(\left(\mathrm{NH}_{4}\right)_{2} \mathrm{SO}_{4}\right)$, oxalic acid ((HOOC)-(COOH)), etc.) at $\mathrm{RH} \sim 90 \%$ to calculate the ALWC at different RHs (10-99\%) in a laboratory, and then compared it with the ALWC simulated from the AIM model. The results retrieved from these two methods showed a significant difference for RH below $85 \%$. Aggarwal et al. (2007) used an H-TDMA to measure the ALWC at the RH of 5 to $95 \%$ generated from the water extracts of ambient aerosol filter samples that were collected by a high volume air sampler.

In this paper, High Humidity Tandem Differential Mobility Analyser (HH-TDMA, Hennig et al., 2005) measurements under high RH (90-98.5\%) conditions are utilized to acquire aerosol hygroscopicity information using the 
$\kappa$-Köhler theory (Petters and Kreidenweis, 2007). The result is used to estimate the size-resolved aerosol growth factors at RH from 20 to $99 \%$, and then combined with the measured PNSD to calculate the ALWC in July-August 2009 in Wuqing area. A comparison is made between the ALWC obtained by the above-described method and the results simulated by the ISORROPIA II model with size-segregated aerosol chemical component information as input. In addition, the influences of both RH and PNSD on the ALWC are analysed in detail.

\section{Data and measurements}

\subsection{Site}

The North China Plain (NCP) has experienced rapid economic developments during the past few decades. Meanwhile, the air pollution in this area has become a very serious problem (Xu et al., 2011). The Haze in China (HaChi) project was jointly sponsored by Peking University and the Leibniz Institute for Tropospheric Research (TROPOS) during July-August 2009 at the Wuqing Meteorological Station $\left(39^{\circ} 23^{\prime} \mathrm{N}, 117^{\circ} 01^{\prime} \mathrm{E}, 7.4 \mathrm{~m}\right.$ a.s.l.). For description of the site and measurements see Liu et al. (2011) and Ran et al. (2011). The time zone that contains this site is in UTC +8 , so all of the time is reported as UTC +8 in this paper. Figure 1 shows the location of Wuqing site, the major neighbouring cities and the average geographical distribution of MODIS (Moderate Resolution Imaging Spectroradiometer) AOD at $550 \mathrm{~nm}$ wavelength in 2009. As shown by the AOD distribution, AOD values are high over the entire NCP (AOD > 0.6). In addition, the AOD distribution is relatively homogeneous over the intercity area. The AOD value is about 0.7 at Wuqing site, which is close to the average AOD of the NCP. Therefore, this site is highly representative of the general situation of aerosol pollution in the NCP.

\subsection{Instrumentation}

The aerosol hygroscopic growth properties at high humidity, the aerosol PNSD at dry state, the aerosol chemical components and the ambient temperature and RH were sampled from 15 July to 15 August 2009. Here the aerosol PNSD at dry state refers to the PNSD measurements which were conducted under RH below $40 \%$. During the campaign, the HH-TDMA and the Twin Differential Mobility Particle Sizer (TDMPS)/Aerodynamic Particle Sizer (APS) for the aerosol hygroscopicity and PNSD measurements were housed in a mobile laboratory consisting of a refitted shipping container. The sample flow was dried to RH less than $40 \%$ before flowing into the laboratory (Tuch et al., 2009). The room temperature of the laboratory was kept steady at $20^{\circ} \mathrm{C}$. The Berner low-pressure impactor (BLPI) for the aerosol filter sampling was placed near the Automatic Weather Station in an open field. The stage films of the BLPI were changed twice a day.

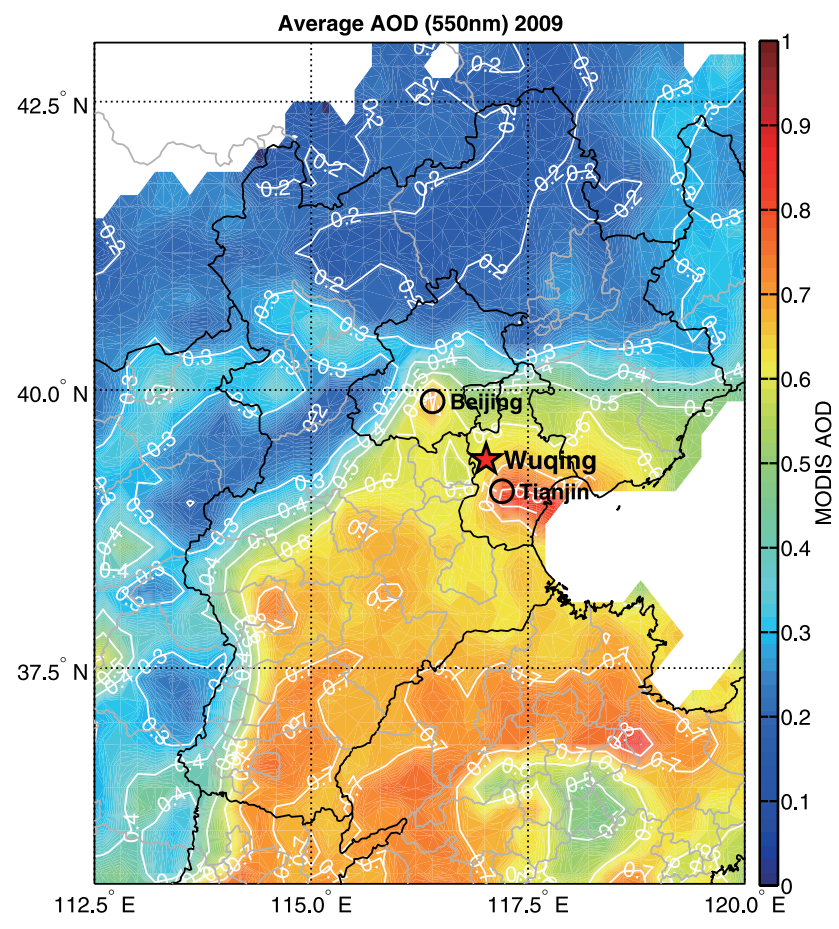

Figure 1. MODIS AOD distribution and the location of the measurement site (red star) and regional mega cities (circle).

Measurements were made from 11:00 to 17:00 LT and from 20:00 to 02:00 LT. The samples were carefully stored at about $-20^{\circ} \mathrm{C}$ for further analysis.

The HH-TDMA is an important instrument in this study, designed to measure the size-resolved aerosol hygroscopic growth characteristics at high RH (90-98.5\%) (Hennig et al., 2005). The basic principle is similar to that of the H-TDMA (Rader and McMurry, 1986). The widely used H-TDMA are not able to hold the RH of aerosols and sheath flow stable, for $\mathrm{RH}>90 \%$. To measure the aerosol hygroscopic growth at high RH, TROPOS used the technique of temperaturecontrolled water bath and re-designed the HH-TDMA based on the H-TDMA.

The TDMPS (Birmili et al., 1999) includes two Hauketype DMAs that have different effective centre rod lengths which measure aerosol particles in size range of $20-800 \mathrm{~nm}$ and 3-20 nm, respectively. The two Condensation Particle Counters are used to count the aerosol particles downstream of the two DMAs. Combining the counts from the two Condensation Particle Counters, the TDMPS can measure the PNSD of aerosol particles from 3-800 nm (electrical mobility diameter). A complete scan of the TDMPS takes $10 \mathrm{~min}$. The APS (Model 3320, TSI, Inc., Shoreview, MN, USA) was used to measure the aerosol size distribution from 0.5 to $10 \mu \mathrm{m}$ aerodynamic particle diameter (Armendariz and Leith, 2002).

Detailed information on the pre-processing of the TDMPS data can be found in Ma et al. (2011). Using the algorithm 
described by DeCarlo et al. (2004), electrical mobility equivalent diameter measured by TDMPS and aerodynamic equivalent diameter measured by APS were transformed to volume equivalent diameter. The density was assumed as $1.7 \mathrm{~g} \mathrm{~cm}^{-3}$ directly. Then the PNSD were interpolated into a logarithmically uniformly spaced diameter from $3 \mathrm{~nm}$ to $10 \mu \mathrm{m}$. Moreover, the PNSD data were adjusted for impaction losses, diffusion losses and gravitational losses. The temporal resolution of the PNSD data was 10 min.

The BLPI segregates aerosols into 10 stages. The sampler segregates diameters by different sized orifices which lead to different flow rates. Every stage is made up of two parts: air flows across the jet hold on the first part and particles with diameters larger than the cut-off diameter of that stage will be collected by the sampling filter on the second part. When the air flow passes through the instrument, particulates with different diameters will impact on different stages with filters collecting them (Hillamo and Kauppinen, 1991). Excluding stage 10 , the measuring range is from $15 \mathrm{~nm}$ to $8 \mu \mathrm{m}$, segregated into nine stages. The lower and upper bounds for each stage are shown in Table 1. For detailed information about the particle size ranges and mean diameters for the individual impactor stages see Liu et al. (2014). By preweighing and then weighing and analysing the films afterwards in the laboratory, the stage-segregated aerosol chemistry information was determined.

\section{Methods}

\subsection{Size-resolved hygroscopic growth factors $(g(D, R H))$ based on HH-TDMA observation}

Particle water uptake can be represented by the Köhler theory (Köhler, 1936). Recently, some single-parameter representations of the Köhler equation have been proposed previously (Rissler et al., 2006; Petters and Kreidenweis, 2007; Wex et al., 2007). In this study, a widely used hygroscopicity parameter $\kappa$ is used to analyse the hygroscopic growth of particles in the subsaturated regime. Based on the Köhler equation, the physical quantities about aerosol hygroscopicity are simplified to $\kappa$ to obtain a new equation, named " $\kappa$-Köhler theory" (Petters and Kreidenweis, 2007). According to this theory, $S(D)$, the saturation ratio over the hydrated particulate solution surface, can be calculated from

$S(D)=\frac{D^{3}-D_{\mathrm{d}}^{3}}{D^{3}-D_{\mathrm{d}}^{3}(1-\kappa)} \exp \left(\frac{4 \sigma_{\mathrm{s} / \mathrm{a}} M_{\mathrm{w}}}{R \rho_{\mathrm{w}} D}\right)$,

where $\sigma_{\mathrm{s} / \mathrm{a}}$ is the surface tension coefficient, $M_{\mathrm{w}}$ is the mole mass of water, $R$ is the universal gas constant, $T$ is the temperature, $\rho_{\mathrm{w}}$ is the density of water, $D_{\mathrm{d}}$ is the diameter of dry particle and $D$ is the diameter of wet particle. $S$ is as same as $\mathrm{RH}$ at this condition. For a known $T$ and $S$, the relationship between $\kappa$ and $g\left(D_{\mathrm{d}}, \mathrm{RH}\right)$, the hygroscopic growth factor at a

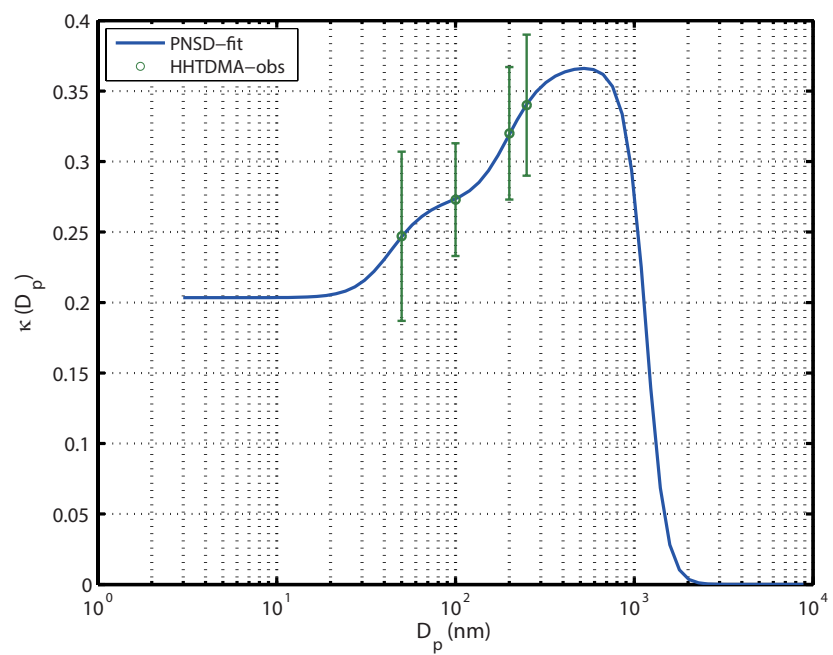

Figure 2. Size-resolved $\kappa$ (blue line) and the corresponding mean values \pm 1 standard deviation of observed $\kappa$ (green circles and error bars) of particles with dry diameters of 50, 100, 200 and $250 \mathrm{~nm}$ during the HaChi summer campaign.

certain diameter $D_{\mathrm{d}}$ and a certain $\mathrm{RH}$, can calculated by

$\kappa=\left(g\left(D_{\mathrm{d}}, \mathrm{RH}\right)^{3}-1\right)\left[\frac{1}{\mathrm{RH}} \exp \left(\frac{4 \sigma_{\mathrm{S} / \mathrm{a}} M_{\mathrm{w}}}{R T \rho_{\mathrm{w}} D_{\mathrm{d}} \cdot g\left(D_{\mathrm{d}}, \mathrm{RH}\right)}\right)-1\right]$,

where $g\left(D_{\mathrm{d}}, \mathrm{RH}\right)=D / D_{\mathrm{d}}$. In this study, the $T$ used to calculate $\kappa$ is set to $293 \mathrm{~K}$ as the room temperature of our container at the site, and $\sigma_{\mathrm{s} / \mathrm{a}}$ is assumed to be the surface tension coefficient between water and air (about $0.0728 \mathrm{~N} \mathrm{~m}^{-1}$ at $293 \mathrm{~K}$ ).

Liu et al. (2011) found that, for a certain particle diameter, the according growth factors varies with $\mathrm{RH}$. The $\kappa$ value, however, does not vary with RH. The HH-TDMA was used to measure the hygroscopic growth factors and the hygroscopicity parameter $\kappa$ at four dry aerosol diameters $(50,100$, 200 and $250 \mathrm{~nm}$ ) in this campaign. Calculations need to be made to derive a size-resolved hygroscopic growth factors. First, a four-mode lognormal distribution is applied to fit the measured PNSD, yielding fitting parameters for each mode (Hussein et al., 2005). Afterwards, assuming that $\kappa$ is constant within the same mode, the measured $\kappa$ can be used to deduce the corresponding $\kappa$ for each of the four modes of the reconstructed PNSDs. Considering that the primary chemical component of the coarse particles is nearly hydrophobic, the $\kappa$ for the coarse mode is assumed to be 0 . Then the sizeresolved $\kappa$ can be calculated by combining the four-mode fitting results with the measured $\kappa$ values at certain particle diameters (Fig. 2). Finally, the size-resolved $\kappa$ is substituted into Eq. (2) to calculate the size-resolved growth factors at 20-99\% RH, respectively. The detail of the fitting and calculating process is described by Chen et al. (2012). 
Table 1. The lower and upper bounds for each stage of the BLPI. They represent the $50 \%$ cut-off aerodynamic diameters.

\begin{tabular}{lrrrrrrrrrr}
\hline Impactor stage & 1 & 2 & 3 & 4 & 5 & 6 & 7 & 8 & 9 & 10 \\
\hline Lower bound $(\mu \mathrm{m})$ & 0.015 & 0.03 & 0.06 & 0.125 & 0.25 & 0.5 & 1 & 2 & 4 & 8 \\
Upper bound $(\mu \mathrm{m})$ & 0.03 & 0.06 & 0.125 & 0.25 & 0.5 & 1 & 2 & 4 & 8 & 16 \\
\hline
\end{tabular}

\subsection{Calculation of ALWC from $g(D, \mathrm{RH})$}

With the assumption of the conservation of volume during the aerosol hygroscopic process, the volume of ALWC is equal to subtracting the volume of dry aerosol particles from that of wet particles. Using the size-resolved hygroscopic growth factors and the PNSD measurement, the ALWC can be calculated:

$\operatorname{ALWC}=\left[\frac{\pi}{6} \sum_{i} N_{i} D_{\mathrm{d}, i}^{3}\left(g\left(D_{\mathrm{d}}, \mathrm{RH}\right)^{3}-1\right)\right] \cdot \rho_{\mathrm{w}}$,

where $N_{i}\left(D_{\mathrm{d}, i}\right)$ represents the number concentration of dry particles of the $i$ th bin, $D_{\mathrm{d}, i}$ is the particle diameter of that bin, and $\rho_{\mathrm{w}}$ is $1 \mathrm{~g} \mathrm{~cm}^{-3}$ in this study. ALWC is given in the unit of $\mathrm{g} \mathrm{m}^{-3}$ of air.

\subsection{Simulation of ALWC from ISORROPIA II model}

ISORROPIA II is a computationally efficient thermodynamic equilibrium model developed recently by Fountoukis and Nenes (2007). All chemical components the BLPI filter sample analysis yielded are considered in this model except for the organic species. Liu et al. (2014) shows that the overall particle hygroscopicity is mostly contributed by inorganic compounds in the NCP and the water-soluble organic compounds play a critical role only for ultrafine particles smaller than $100 \mathrm{~nm}$. The thermodynamics of the crustal species including $\mathrm{Ca}^{2+}, \mathrm{K}^{+}$and $\mathrm{Mg}^{2+}$ have been added to the model's treatment components along with $\mathrm{NH}_{4}^{+}, \mathrm{Na}^{+}, \mathrm{SO}_{4}^{2-}, \mathrm{NO}_{3}^{-}$, $\mathrm{Cl}^{-}$and $\mathrm{H}_{2} \mathrm{O}$, but organic species are not taken into account. ISORROPIA II is used to model the ALWC (the temperature was set to $293 \mathrm{~K}$ ). ISORROPIA II exhibits robust and rapid convergence under all conditions, with especially prominent performance on computational speed. Based on its computational rigour and performance on computational speed, ISORROPIA II appears to be an extremely desirable choice for large-scale atmospheric transport and air quality models (Fountoukis and Nenes, 2007). The ISORROPIA II model can simulate the ALWC with the input of aerosol chemical composition measured by BLPI sampling (Liu et al., 2014).

ISORROPIA II model assumes that the aerosol curvature effect can be ignored and the water uptake of aerosols has no effect to the ambient vapour pressure. Consequently, the water activity $a_{\mathrm{w}}$ is equal to the ambient RH caused by the phase equilibrium between gas and aerosols (Seinfeld and
Pandis, 2006):

$a_{\mathrm{w}}=\mathrm{RH}$.

The water uptake of aerosols is calculated with the ZSR hypothesis

$\mathrm{ALWC}=\sum_{i} \frac{M_{i}}{m_{\mathrm{o} i}\left(a_{\mathrm{W}}\right)}$,

where $M_{i}$ is the mole concentration of the electrolyte $i$ $\left(\mathrm{mol} \mathrm{m} \mathrm{m}^{-3}\right.$ air) and $m_{\mathrm{o} i}\left(a_{\mathrm{w}}\right)$ is the corresponding molality of the binary solution of the electrolyte $i$ under the same $a_{\mathrm{w}}$ with complex solution.

\section{Results and discussion}

\subsection{Comparison between the two methods to estimate the ALWC}

The aerosol liquid water content calculated from the measured hygroscopic growth factors is compared with the results modelled with ISORROPIA II. As can be seen in Fig. 3, at low RH, the ISORROPIA II ALWC values are much smaller than those calculated from the growth factors. With increasing $\mathrm{RH}$, the two results gradually converge. For $\mathrm{RH}$ over $60 \%$, the results from the two methods agree well with a correlation coefficient $R$ of 0.96 . The possible explanations for these results can be summarized as follows.

First, the more complicated the aerosol chemical composition, the lower the DRH of aerosol becomes (Seinfeld and Pandis, 2006). Thus, due to the limited types of inorganic species considered in the ISORROPIA II model, the modelled DRH is much higher than that in the real atmosphere. For RH below the modelled DRH (around $60 \%$ ), aerosol is predicted to be still in a dry state, not significantly hydrated, and with small ALWC, whereas in the real atmosphere it might have already crossed over to a hydrated state. The modelled ALWC are therefore much lower than those calculated with the growth factors at RH below the simulated DRH.

Furthermore, ISORROPIA II assumes that the aerosol is completely dry at the beginning of the simulation, then dissolves each of its salt components and simulates water uptake as the ambient RH increases. This solution dynamics is different from that of some other models, like SCAPE2, which leads to the fact that the ISORROPIA II modelled ALWC 


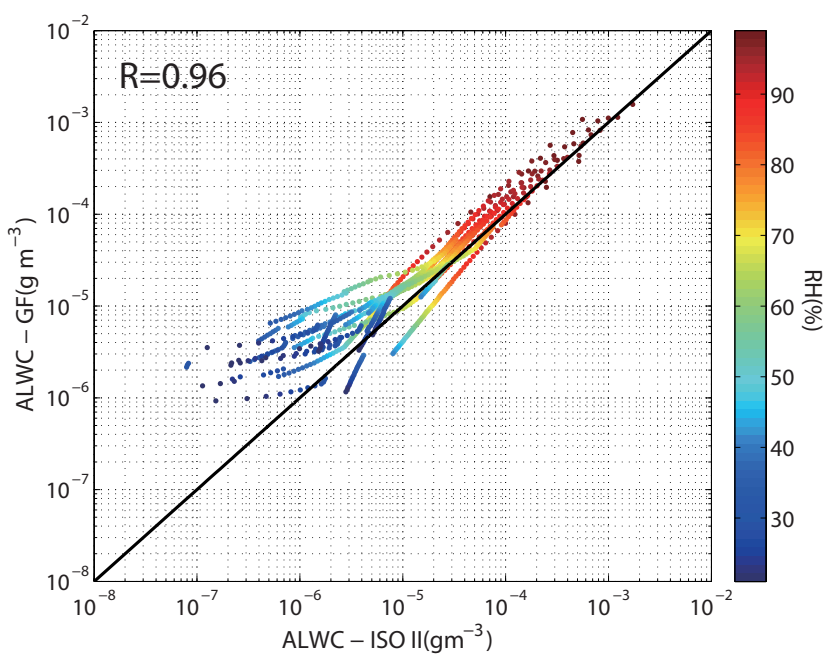

Figure 3. Comparison between ALWC calculated from measured growth factors (ALWC-GF) and modelled with ISORROPIA II (ALWC-ISO II); the colour of the dots present their corresponding RHs; the solid line shows the $1: 1$ line.

results under low RH are not only lower than the growth factors calculated result, but also lower than that modelled by SCAPE2 (Fountoukis and Nenes, 2007).

The modelled ALWC is closer to the calculated one at high $\mathrm{RH}$. The shape and mixing state of aerosols is not considered in the ISORROPIA II and the effect of non-spheroids is also ignored. Thus, the "inverse Kelvin effect" is disregarded in the ISORROPIA II. This effect enhances the water uptake of real aerosols compared with the flat surface that is assumed in ISORROPIA II and also leads to a decrease in the DRH (Sjogren et al., 2007).On the other hand, the $\kappa$ values used to calculate the size-resolved hygroscopic growth factors are measured under high RH conditions (>90\%), so the deliquescence process is not considered in the calculation. For RH below the DRH, a discrepancy may exist between the calculated ALWC and the true value.

\subsection{Time series and diurnal variation of liquid water content}

Figure 4a shows the time series of ALWC calculated from the growth factors at ambient $\mathrm{RH}$ during the HaChi summer campaign. During the campaign, the maximum value of ALWC is $9.71 \times 10^{-4} \mathrm{~g} \mathrm{~m}^{-3}$, with an average value of $(1.69 \pm 1.64) \times 10^{-4} \mathrm{~g} \mathrm{~m}^{-3}$. Although these values are much lower than the ALWC in clouds measured by aircraft over this region (Deng et al., 2009), the significance of ALWC cannot be ignored. The life time of a cloud is about several hours, but aerosols may last for several days in the air (Seinfeld and Pandis, 2006). The ALWC also plays an important role in atmospheric chemistry and radiation in the NCP due to high aerosol loading and the long lifetime of aerosols.

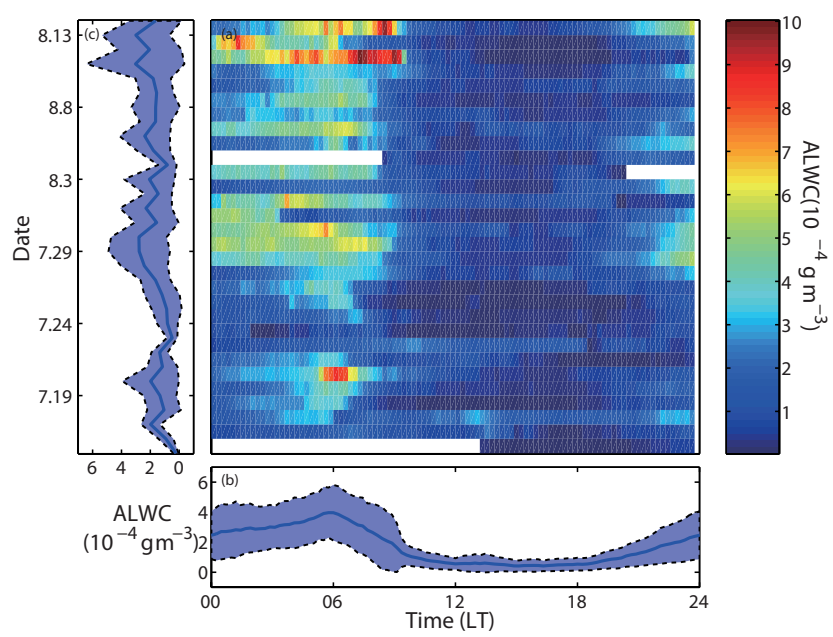

Figure 4. (a) Time series of the estimated ALWC during the HaChi summer campaign (denoted by the colour). (b) Diurnal variation of the estimated ALWC. (c) Daily averaged time series of the estimated ALWC. The blue region of the time and diurnal series denotes \pm 1 standard deviation.

The calculated ALWC shows an obvious diurnal variation (Fig. 4b). During the daytime, the ALWC stays at low level. After 18:00 LT, the ALWC begins to rise to relatively high values, since particle emissions are accumulated in the narrowed surface layer with RH increasing simultaneously. The maximum ALWC appears at 06:00 LT. Afterwards it drops slightly as a result of increased surface temperature that leads to the growth of the boundary layer and reduces the relative humidity (Stull, 1988). Due to the vehicle combustion resulting from rush hours, the ALWC does not decrease very quickly during 06:00-09:00 LT. After that period, a rapid reduction in the ALWC can be observed. The growth factors of most particles vary little in a day, hence have only slight influence on the diurnal variation of the ALWC. During the campaign, no regular variation patterns of the daily averaged ALWC could be found (Fig. 4c).

\subsection{Factors influencing the ALWC}

\subsubsection{Impacts of RH}

According to Eq. (3), the absolute value of ALWC depends to a great extent on the dry aerosol volume. To evaluate how RH impacts the ALWC, the influence of the dry volume of aerosols has to be removed. Consequently, a physical quantity called relative ALWC is defined as

Relative ALWC $=\mathrm{ALWC} / C_{\text {volume }}$,

where $C_{\text {volume }}$ represents the volume concentration of dry aerosol particles.

The physical meaning of the relative ALWC is the mass of water absorbed by a unit volume of dry aerosols. A significant positive correlation can be found between the relative 


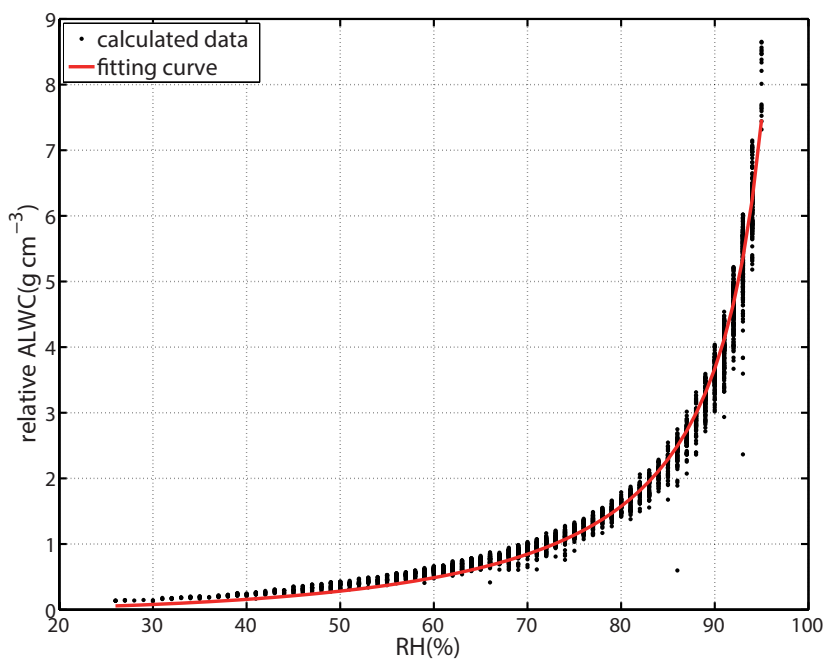

Figure 5. The relationship between relative ALWC and RH. Relative ALWC is defined as the mass of water absorbed by unit volume of dry aerosols. The black dots represent the relative ALWC calculated with ALWC and aerosol volume concentration. The red line shows the curve fitted with Eq. (7).

ALWC and RH using all of the calculated ALWC and the according aerosol volume concentration and ambient $\mathrm{RH}$ values during the HaChi campaign (Fig. 5). Under low RH, the relative ALWC rises slowly with RH. When RH exceeds $80 \%$, the relative ALWC increases rapidly with RH, which means that $\mathrm{RH}$ is an important influencing factor in the ALWC variation.

To describe the relationship between relative ALWC and $\mathrm{RH}$, a two-parameter fitted function is used with the relative ALWC and the ambient RH (Fig. 5):

Relative ALWC $=a\left((1-\mathrm{RH})^{b \mathrm{RH}}-1\right)$,

where the fitted parameters $a$ and $b$ are 0.91 and -0.78 , respectively. The coefficient of determination $R^{2}$ is 0.99 approximately.

\subsubsection{Impacts of PNSD}

PNSD is another important factor influencing the aerosol liquid water content. The aerosol particles are separated into four modes according to their different origins (Whitby, 1978; Birmili et al., 2001): nucleation mode $(<30 \mathrm{~nm})$, Aitken mode $(30-110 \mathrm{~nm})$, accumulation mode $(110 \mathrm{~nm}-$ $1 \mu \mathrm{m})$ and coarse mode $(>1 \mu \mathrm{m})$. The relationship between ALWC and the number concentration of each mode has been analysed to evaluate the impacts of PNSD on the ALWC. These relationships under five different $\mathrm{RH}$ conditions are discussed based on the discussion of RH impact above. Then the ALWC is linearly fitted with the number concentrations of particles in each mode under varying RH conditions.

Table 2 shows the coefficient of determination of the linear regressions of ALWC and particulate number concentra-

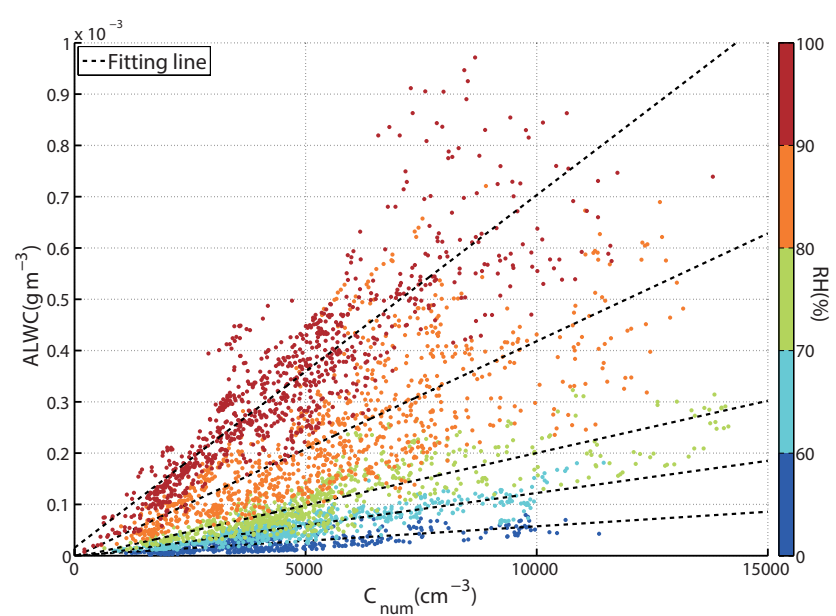

Figure 6. Coloured dots show the variation of the ALWC with corresponding number concentrations of accumulation mode particles, with the colour segregated by the RH stages. The dashed lines represent the fitting results in accumulation mode under varying $\mathrm{RH}$ conditions.

Table 2. The coefficient of determination of each aerosol mode under different RH conditions.

\begin{tabular}{rcccc}
\hline RH (\%) & \multicolumn{4}{c}{ Coefficient of determination $\left(R^{2}\right)$} \\
& $\begin{array}{c}\text { Nucleation } \\
\text { mode }\end{array}$ & $\begin{array}{c}\text { Aitken } \\
\text { mode }\end{array}$ & $\begin{array}{c}\text { Accumulation } \\
\text { mode }\end{array}$ & $\begin{array}{c}\text { Coarse } \\
\text { mode }\end{array}$ \\
\hline$\leq 60$ & 0.16 & 0.02 & 0.54 & 0.35 \\
$60-70$ & 0.11 & 0.01 & 0.76 & 0.59 \\
$70-80$ & 0.10 & 0.01 & 0.74 & 0.58 \\
$80-90$ & 0.11 & 0.10 & 0.62 & 0.48 \\
$>90$ & 0.04 & 0.32 & 0.78 & 0.35 \\
\hline
\end{tabular}

tions. The $R^{2}$ values of the nucleation and the Aitken mode particles are mostly less than 0.2 under all the RH conditions, which suggests that the particle number concentrations of those two modes have little influence on the ALWC due to their small volume concentration and low hygroscopicity. The hygroscopicity of aerosol particles in these two modes is relatively low because of their origins (Swietlicki et al., 1999). For RH $>90 \%$, the coefficient of determination of the Aitken mode particles is 0.32 and is much higher than the $R^{2}$ values under other $\mathrm{RH}$ conditions. This is because the more-hygroscopic particles in the Aitken mode absorb much more water when RH is higher than $90 \%$. Freshly emitted hydrophobic particles such as externally mixed black carbon particles are mostly in the fine modes. Besides, the significant Kelvin effect also leads to higher hygroscopic growth factors for particles in the coarse mode than for those in fine modes (Väkevä et al., 2002). For the coarse mode, the $R^{2}$ are between 0.3 and 0.6 under all the RH conditions. This shows an existent but not remarkable correlation between the ALWC and the number concentration. Although 
some aerosols in the coarse mode are water soluble and have certain impacts on the ALWC, nearly hydrophobic aerosols, such as dust particles, contribute a large number fraction to the coarse mode (Hussein et al., 2004; Liu et al., 2008, 2014).

The $R^{2}$ for the accumulation mode is significantly higher than those for the other three modes (Fig. 6). All the results are above 0.6 at $\mathrm{RH}>60 \%$. This indicates that the number concentration of the accumulation mode plays a significant role in the ALWC variation. Accumulation mode particles are mostly aged, secondary aerosol and are transported within boundary layer and subjected to cloud processing, which leads to higher hygroscopicity than those of the nucleation and Aitken mode aerosols (Swietlicki et al., 1999; Vignati et al., 2004). Accumulation mode particles also have a large volume fraction of aerosols.

\section{Summary}

ALWC is an important physical quantity that can significantly influence aerosol optical and chemical properties. However, direct measurement of ALWC is hard to achieve, especially under high RH conditions. In this paper, a novel method to calculate the ALWC from aerosol hygroscopicity measurements is proposed based on the size-resolved aerosol hygroscopic growth factors, PNSD, and RH. The size-resolved aerosol growth factors are obtained using the $\kappa$-Köhler theory with the HH-TDMA measurements under high RH (90-98.5\%).

The ALWC is also modelled using ISORROPIA II model with the input of measured aerosol chemistry data during the summertime field campaign in 2009. Comparisons between the ALWC results calculated by hygroscopic growth factors and modelled by ISORROPIA II show that under low RH, the modelled results are much smaller than the calculated ones. With the increase of $\mathrm{RH}$, the results from these two methods gradually converge together. They agree well with each other at $\mathrm{RH}$ higher than $60 \%$, with a correlation coefficient of 0.96 .

The maximum value of ALWC calculated with aerosol hygroscopicity measurements in the NCP between July and August 2009 reaches $9.71 \times 10^{-4} \mathrm{~g} \mathrm{~m}^{-3}$, with an average value of $1.69 \times 10^{-4} \mathrm{~g} \mathrm{~m}^{-3}$. The ALWC experiences significant diurnal variations at Wuqing site, with lower values during daytime and higher ones during night-time. Aerosol liquid water content is highly related to the relative humidity. The contribution to the aerosol liquid water content from the accumulation mode is dominating among all the aerosol particle modes.
Acknowledgements. This work is supported by the National 973 project of China (2011CB403402), the National Natural Science Foundation of China under grant no. 41375134, the Beijing Natural Science Foundation (8131003), the Beijing Municipal Science and Technology Plan project no. Z131100006113013, and the Tianjin Municipal Science and Technology support programme (13ZCZDSF02100).

Edited by: D. Covert

\section{References}

Aggarwal, S. G., Mochida, M., Kitamori, Y., and Kawamura, K.: Chemical Closure Study on Hygroscopic Properties of Urban Aerosol Particles in Sapporo, Japan, Environ. Sci. Technol., 41, 6920-6925, 2007.

Aklilu, Y., Mozurkewich, M., Prenni, A. J., Kreidenweis, S. M., Alfarra, M. R., Allan, J. D., Anlauf, K., Brook, J., Leaitch, W. R., Sharma, S., Boudries, H., and Worsnop, D. R.: Hygroscopicity of particles at two rural, urban influenced sites during Pacific 2001: Comparison with estimates of water uptake from particle composition, Atmos. Environ., 40, 2650-2661, 2006.

Arellanes, C., Paulson, S. E., Fine, P. M., and Sioutas, C.: Exceeding of Henry's Law by Hydrogen Peroxide Associated with Urban Aerosols, Environ. Sci. Technol., 40, 4859-4866, 2006.

Armendariz, A. J. and Leith, D.: Concentration measurement and counting efficiency for the aerodynamic particle sizer 3320 , J. Aerosol. Sci., 33, 133-148, 2002.

Bassett, M. and Seinfeld, J. H.: Atmospheric equilibrium model of sulfate and nitrate aerosols, Atmos. Environ., 17, 2237-2252, 1983.

Birmili, W., Stratmann, F., and Wiedensohler, A.: Design of a DMA-based size spectrometer for a large particle size range and stable operation, J. Aerosol Sci., 30, 549-553, 1999.

Birmili, W., Wiedensohler, A., Heintzenberg, J., and Lehmann, K.: Atmospheric particle number size distribution in central Europe: Statistical relations to air masses and meteorology, J. Geophys. Res.-Atmos., 106, 32005-32018, 2001.

Chang, C. T., Tsai, C. J., Lee, C. T., Chang, S. Y., Cheng, M. T., and Chein, H. M.: Differences in $\mathrm{PM}_{10}$ concentrations measured by $\beta$-gauge monitor and hi-vol sampler, Atmos. Environ., 35, 57415748, 2001.

Chen, J., Zhao, C. S., Ma, N., Liu, P. F., Göbel, T., Hallbauer, E., Deng, Z. Z., Ran, L., Xu, W. Y., Liang, Z., Liu, H. J., Yan, P., Zhou, X. J., and Wiedensohler, A.: A parameterization of low visibilities for hazy days in the North China Plain, Atmos. Chem Phys., 12, 4935-4950, doi:10.5194/acp-12-4935-2012, 2012.

Cheng, Y. F., Wiedensohler, A., Eichler, H., Heintzenberg, J., Tesche, M., Ansmann, A., Wendisch, M., Su, H., Althausen, D., Herrmann, H., Gnauk, T., Brüggemann, E., Hu, M., and Zhang, Y. H.: Relative humidity dependence of aerosol optical properties and direct radiative forcing in the surface boundary layer at Xinken in Pearl River Delta of China: An observation based numerical study, Atmos. Environ., 42, 6373-6397, 2008.

DeCarlo, P. F., Slowik, J. G., Worsnop, D. R., Davidovits, P., and Jimenez, J. L.: Particle Morphology and Density Characterization by Combined Mobility and Aerodynamic Diameter Measurements. Part 1: Theory, Aerosol. Sci. Tech., 38, 1185-1205, 2004. 
Deng, Z., Zhao, C., Zhang, Q., Huang, M., and Ma, X.: Statistical analysis of microphysical properties and the parameterization of effective radius of warm clouds in Beijing area, Atmos. Res., 93, 888-896, 2009.

Dougle, P. G., Vlasenko, A. L., Veefkind, J. P., and Brink, H. M. T.: Humidity dependence of the light scattering by mixtures of ammonium nitrate, ammonium sulfate and soot, J. Aerosol. Sci., 27, 513-514, 1996.

Engelhart, G. J., Hildebrandt, L., Kostenidou, E., Mihalopoulos, N., Donahue, N. M., and Pandis, S. N.: Water content of aged aerosol, Atmos. Chem. Phys., 11, 911-920, doi:10.5194/acp-11911-2011, 2011.

Fountoukis, C. and Nenes, A.: ISORROPIA II: a computationally efficient thermodynamic equilibrium model for $\mathrm{K}^{+}$ $\mathrm{Ca}^{2+}-\mathrm{Mg}^{2+}-\mathrm{NH}_{4}^{+}-\mathrm{Na}^{+}-\mathrm{SO}_{4}^{2}-\mathrm{NO}_{3}^{-}-\mathrm{Cl}^{-}-\mathrm{H}_{2} \mathrm{O}$ aerosols, Atmos. Chem. Phys., 7, 4639-4659, doi:10.5194/acp-7-4639-2007, 2007.

Gelencsér and Varga: Evaluation of the atmospheric significance of multiphase reactions in atmospheric secondary organic aerosol formation, Atmos. Chem. Phys., 5, 2823-2831, doi:10.5194/acp5-2823-2005, 2005.

Gysel, M., Crosier, J., Topping, D. O., Whitehead, J. D., Bower, K. N., Cubison, M. J., Williams, P. I., Flynn, M. J., McFiggans, G. B., and Coe, H.: Closure study between chemical composition and hygroscopic growth of aerosol particles during TORCH2, Atmos. Chem. Phys., 7, 6131-6144, doi:10.5194/acp-7-61312007, 2007.

Hennig, T., Massling, A., Brechtel, F. J., and Wiedensohler, A.: A Tandem DMA for highly temperature-stabilized hygroscopic particle growth measurements between $90 \%$ and $98 \%$ relative humidity, J. Aerosol. Sci., 36, 1210-1223, 2005.

Hennigan, C. J., Bergin, M. H., Dibb, J. E., and Weber, R. J.: Enhanced secondary organic aerosol formation due to water uptake by fine particles, Geophys. Res. Lett., 35, L18801, doi:10.1029/2008g1035046, 2008.

Hillamo, R. E. and Kauppinen, E. I.: On the Performance of the Berner Low Pressure Impactor, Aerosol Sci. Tech., 14, 33-47, 1991.

Hussein, T., Puustinen, A., Aalto, P. P., Mäkelä, J. M., Hämeri, K., and Kulmala, M.: Urban aerosol number size distributions, Atmos. Chem. Phys., 4, 391-411, doi:10.5194/acp-4-391-2004, 2004.

Hussein, T., Dal Maso, M., Petäjä, T., Koponen, I. K., Paatero, P., Aalto, P. P., Hämeri, K., and Kulmala, M.: Evaluation of an automatic algorithm for fitting the particle number size distributions, Boreal Environ. Res., 10, 337-355, 2005.

Jacobson, M. Z., Tabazadeh, A., and Turco, R. P.: Simulating equilibrium within aerosols and nonequilibrium between gases and aerosols, J. Geophys. Res.-Atmos., 101, 9079-9091, 1996.

Kim, Y. P., Seinfeld, J. H., and Saxena, P.: Atmospheric GasAerosol Equilibrium I. Thermodynamic Model, Aerosol Sci. Tech., 19, 157-181, 1993.

Kitamori, Y., Mochida, M., and Kawamura, K.: Assessment of the aerosol water content in urban atmospheric particles by the hygroscopic growth measurements in Sapporo, Japan, Atmos. Environ., 43, 3416-3423, 2009.

Köhler, H.: The nucleus in and the growth of hygroscopic droplets, T. Faraday Soc., 32, 1152-1161, 1936.
Kreidenweis, S. M., Petters, M. D., and DeMott, P. J.: Singleparameter estimates of aerosol water content, Environ. Res. Lett., 3, 035002, doi:10.1088/1748-9326/3/3/035002, 2008.

Jung, J., Lee, H., Kim, Y. J., Liu, X., Zhang, Y., Gu, J., and Fan, S.: Aerosol chemistry and the effect of aerosol water content on visibility impairment and radiative forcing in Guangzhou during the 2006 Pearl River Delta campaign, J. Environ. Manage., 90, 3231-3244, 2009.

Liu, S., Hu, M., Wu, Z., Wehner, B., Wiedensohler, A., and Cheng, Y.: Aerosol number size distribution and new particle formation at a rural/coastal site in Pearl River Delta (PRD) of China, Atmos. Environ., 42, 6275-6283, 2008.

Liu, H. J., Zhao, C. S., Nekat, B., Ma, N., Wiedensohler, A., van Pinxteren, D., Spindler, G., Müller, K., and Herrmann, H.: Aerosol hygroscopicity derived from size-segregated chemical composition and its parameterization in the North China Plain, Atmos. Chem. Phys., 14, 2525-2539, doi:10.5194/acp-14-25252014, 2014.

Liu, P. F., Zhao, C. S., Göbel, T., Hallbauer, E., Nowak, A., Ran, L., Xu, W. Y., Deng, Z. Z., Ma, N., Mildenberger, K., Henning, S., Stratmann, F., and Wiedensohler, A.: Hygroscopic properties of aerosol particles at high relative humidity and their diurnal variations in the North China Plain, Atmos. Chem. Phys., 11, 3479-3494, doi:10.5194/acp-11-3479-2011, 2011.

Ma, N., Zhao, C. S., Nowak, A., Müller, T., Pfeifer, S., Cheng, Y. F., Deng, Z.Z., Liu, P. F., Xu, W. Y., Ran, L., Yan, P., Göbel, T., Hallbauer, E., Mildenberger, K., Henning, S., Yu, J., Chen, L. L., Zhou, X. J., Stratmann, F., and Wiedensohler, A.: Aerosol optical properties in the North China Plain during HaChi campaign: an in-situ optical closure study, Atmos. Chem. Phys., 11, 59595973, doi:10.5194/acp-11-5959-2011, 2011.

Martin, S. T.: Phase Transitions of Aqueous Atmospheric Particles, Chem. Rev., 100, 3403-3454, 2000.

Meier, J., Wehner, B., Massling, A., Birmili, W., Nowak, A., Gnauk, T., Brüggemann, E., Herrmann, H., Min, H., and Wiedensohler, A.: Hygroscopic growth of urban aerosol particles in Beijing (China) during wintertime: a comparison of three experimental methods, Atmos. Chem. Phys., 9, 6865-6880, doi:10.5194/acp9-6865-2009, 2009.

Nenes, A., Pandis, S., and Pilinis, C.: ISORROPIA: A New Thermodynamic Equilibrium Model for Multiphase Multicomponent Inorganic Aerosols, Aquat. Geochem., 4, 123-152, 1998.

Petters, M. D. and Kreidenweis, S. M.: A single parameter representation of hygroscopic growth and cloud condensation nucleus activity, Atmos. Chem. Phys., 7, 1961-1971, doi:10.5194/acp-71961-2007, 2007.

Rader, D. J. and McMurry, P. H.: Application of the tandem differential mobility analyzer to studies of droplet growth or evaporation, J. Aerosol. Sci., 17, 771-787, 1986.

Ran, L., Zhao, C. S., Xu, W. Y., Lu, X. Q., Han, M., Lin, W. L., Yan, P., Xu, X. B., Deng, Z. Z., Ma, N., Liu, P. F., Yu, J., Liang, W. D., and Chen, L. L.: VOC reactivity and its effect on ozone production during the HaChi summer campaign, Atmos. Chem. Phys., 11, 4657-4667, doi:10.5194/acp-11-4657-2011, 2011.

Rissler, J., Vestin, A., Swietlicki, E., Fisch, G., Zhou, J., Artaxo, P., and Andreae, M. O.: Size distribution and hygroscopic properties of aerosol particles from dry-season biomass burning in Amazonia, Atmos. Chem. Phys., 6, 471-491, doi:10.5194/acp6-471-2006, 2006. 
Saxena, P., Belle Hudischewskyj, A., Seigneur, C., and Seinfeld, J. H.: A comparative study of equilibrium approaches to the chemical characterization of secondary aerosols, Atmos. Environ., 20, 1471-1483, 1986.

Seinfeld, J. and Pandis, S.: Atmospheric chemistry and physics: from air pollution to climate change, Wiley, Inc., New Jersey, USA, p. 450, 2006.

Sjogren, S., Gysel, M., Weingartner, E., Baltensperger, U., Cubison, M. J., Coe, H., Zardini, A. A., Marcolli, C., Krieger, U. K., and Peter, T.: Hygroscopic growth and water uptake kinetics of twophase aerosol particles consisting of ammonium sulfate, adipic and humic acid mixtures, J. Aerosol. Sci., 38, 157-171, 2007.

Stokes, R. H. and Robinson, R. A.: Interactions in Aqueous Nonelectrolyte Solutions. I. Solute-Solvent Equilibria, J. Phys. Chem., 70, 2126-2131, doi:10.1021/j100879a010, 1966.

Stull, R. B.: An Introduction to Boundary Layer Meteorology, Springer, New York, USA, p. 670, 1988.

Swietlicki, E., Zhou, J., Berg, O. H., Martinsson, B. G., Frank, G., Cederfelt, S. I., Dusek, U., Berner, A., Birmili, W., Wiedensohler, A., Yuskiewicz, B., and Bower, K. N.: A closure study of submicrometer aerosol particle hygroscopic behaviour, Atmos. Res., 50, 205-240, 1999.

Topping, D. O., McFiggans, G. B., and Coe, H.: A curved multicomponent aerosol hygroscopicity model framework: Part 1 - Inorganic compounds, Atmos. Chem. Phys., 5, 1205-1222, doi:10.5194/acp-5-1205-2005, 2005a.

Topping, D. O., McFiggans, G. B., and Coe, H.: A curved multicomponent aerosol hygroscopicity model framework: Part 2 - Including organic compounds, Atmos. Chem. Phys., 5, 1223-1242, doi:10.5194/acp-5-1223-2005, 2005b.

Tuch, T. M., Haudek, A., Müller, T., Nowak, A., Wex, H., and Wiedensohler, A.: Design and performance of an automatic regenerating adsorption aerosol dryer for continuous operation at monitoring sites, Atmos. Meas. Tech., 2, 417-422, doi:10.5194/amt-2-417-2009, 2009.
Väkevä, M., Kulmala, M., Stratmann, F., and Hämeri, K.: Field measurements of hygroscopic properties and state of mixing of nucleation mode particles, Atmos. Chem. Phys., 2, 55-66, doi:10.5194/acp-2-55-2002, 2002.

Vignati, E., Wilson, J., and Stier, P.: M7: An efficient sizeresolved aerosol microphysics module for large-scale aerosol transport models, J. Geophys. Res.-Atmos., 109, D22202, doi:10.1029/2003JD004485, 2004.

Wex, H., Hennig, T., Salma, I., Ocskay, R., Kiselev, A., Henning, S., Massling, A., Wiedensohler, A., and Stratmann, F.: Hygroscopic growth and measured and modeled critical super-saturations of an atmospheric HULIS sample, Geophys. Res. Lett., 34, L02818, doi:10.1029/2006GL028260, 2007.

Wexler, A. S. and Clegg, S. L.: Atmospheric aerosol models for systems including the ions $\mathrm{H}^{+}, \mathrm{NH}_{4}^{+}, \mathrm{Na}^{+}, \mathrm{SO}_{4}^{2-}, \mathrm{NO}_{3}^{-}, \mathrm{Cl}^{-}$, $\mathrm{Br}^{-}$, and $\mathrm{H}_{2} \mathrm{O}$, J. Geophys. Res.-Atmos., 107, ACH 14-11-ACH 14-14, 2002.

Wexler, A. S. and Seinfeld, J. H.: Second-generation inorganic aerosol model, Atmos. Environ. A-Gen., 25, 2731-2748, 1991.

Whitby, K. T.: The physical characteristics of sulfur aerosols, Atmos. Environ., 12, 135-159, 1978.

Xu, W. Y., Zhao, C. S., Ran, L., Deng, Z. Z., Liu, P. F., Ma, N., Lin, W. L., Xu, X. B., Yan, P., He, X., Yu, J., Liang, W. D., and Chen, L. L.: Characteristics of pollutants and their correlation to meteorological conditions at a suburban site in the North China Plain, Atmos. Chem. Phys., 11, 4353-4369, doi:10.5194/acp-114353-2011, 2011.

Zhang, Y., Seigneur, C., Seinfeld, J. H., Jacobson, M., Clegg, S. L., and Binkowski, F. S.: A comparative review of inorganic aerosol thermodynamic equilibrium modules: similarities, differences, and their likely causes, Atmos. Environ., 34, 117-137, 2000. 